\title{
A LUZ NATURAL COMO ESTRATÉGIA DE REABILITAÇÃO
}

\author{
ROMERO, Marta Adriana Bustos
}

\section{RESUMO}

Este artigo visa examinar, dentro de uma perspectiva Bioclimática, os elementos que permitem tratar da luz natural como componente essencial de projeto. O sitio de Brasília e as especiais condições ambientais e paisagísticas do lugar são particularmente relevantes para o objetivo deste trabalho. Com estes conceitos, realizamos avaliações integradas de edifícios do campus da UNB, o Instituto Central de Ciências - ICC e a Faculdade de Tecnologia - FT. Verificamos duas formas de trabalhar a luz em Brasília, em função do tratamento do envoltório, a transparência-claridade e a opacidadepenumbra e os pequenos contrastes da luz. Esses elementos foram utilizados para analisar tanto a forma técnica quanto a poética da iluminação natural, numa ação projetual de reabilitação ambiental integrada, que trazemos para reflexão neste artigo.

Palavras-chave: bioclimatismo, Brasília

\begin{abstract}
This article aims at examining, in a bioclimatic perspective, the elements that permit dealing with natural light as essential component of projects. Brasilia site and the special environmental and landscape conditions of the place are especially relevant to the objective of this paper. With these concepts, we made integrated evaluations of buildings of UNB's Campus, the Central Institute of Science - ICC and Technology Faculty - FT. We verified two forms of working with light in Brasilia, in function of the, wrapping treatment, the transparency - lightning and the opacitysemidarkness and the small contrasts of light. These elements were used to analyze not only the technical form but also the poetics of natural illumination, in a project action of integrated environment rehabilitation that we bring into reflection in this article.
\end{abstract}

Key words: Rehabilitation, bioclimatic,
Brasilia

\section{INTRODUÇÃO}

A luz natural sempre teve conotações históricas de pureza, conhecimento eglória. Em diferentes graus, na antiguidade, a luz era admitida só quando era desejada; em geral, as áreas iluminadas brilhantemente correspondiam a lugares especiais. $\mathrm{O}$ espaço iluminado surge e vibra com a passagem da iluminação natural, confrontando os aspectos puramente ópticos com as respostas que sua natureza imaginativa cria, no qual o universo das sombras tem um papel decisivo na criação de significados, por exemplo, as múltiplas tonalidades da sombra que, em última instância, são as que proporcionam ao espaço sua imagem característica. $\mathrm{O}$ observador contribui com a excitação produzida pelo ato de observação e de participação no espaço que ele analisa.

A luz natural, apesar de não ser suscetível à medição sem instrumentos precisos, pode ser utilizada no ato de projetar, uma vez que a observação sensível proporciona o equivalente de uma medida, como afirmávamos quando tratávamos da arquitetura bioclimática do espaço público. A luz determina a atmosfera ou "gênio" do lugar. Assim, por exemplo, no deserto equatorial, a intensidade da luz é tão forte e as sombras tão curtas, que os objetos vibram e se dissolvem. A luz do Mediterrâneo chega aos espaços com sua presença dourada e faz com que os objetos se destaquem fortemente. Já nos bosques do Norte, a luz é filtrada por nuvens e pelas folhas das árvores até compor modelos formados por porções e largas sombras escuras. (ROMERO, 2001)

Ogenius loci, ou espírito dolugaréo conceito usado para indicar o caráter significativo do lugar que o torna um habitat seguro e amigável psicologicamente. Segundo Norberg - Schulz: "Quando o ambiente é 
significante o homem sente-se em casa". Identificar o caráter $^{1}$ de uma região torna-se imprescindível para alcançar a sustentabilidade do espaço construído, pois, além da conservação da natureza, temos também que adotar práticas locais, tradicionais e endógenas, ou melhor, recuperar o espírito do lugar, (cf. Romero 2006b)

A luz, além de criar a atmosfera do lugar, reforça os laços do habitante com o sitio, permitindo que exista senso de lugar e vinculo com o contexto. Uma avaliação integrada dos elementos térmicos, da luz, do som e da cor do ambiente permite a correta interpretação das necessidades do mesmo. Assim constitui-se a concepção Bioclimática, que pode ser definida como aquela que abriga princípios de desenho que utilizam a adequação ao lugar e à cultura do lugar como parâmetro fundamental (ROMERO, 2001). O sitio de Brasília e as especiais condições ambientais e paisagísticas do lugar são particularmente relevantes para o objetivo deste trabalho, que visa examinar os elementos que permitem tratar da luz como componente essencial de projeto. Com este conceito, realizamos avaliações integradas de espaços do campus da UNB numa ação projetual de reabilitação ambiental integrada, que trazemos para reflexão neste artigo.

Verificamos duas formas de trabalhar a luz em Brasília, em função do tratamento do envoltório, a transparência-claridade e a opacidade-penumbra e os pequenos contrastes da luz. Esses elementos foram utilizados paraanalisartantoaforma técnica quanto a poética de edifícios do campus da UNB que eram objeto da avaliação em geral, assim como o desempenho da iluminação natural no Instituto Central de Ciências ICC e na Faculdade de Tecnologia - FT, em particular.

Este artigo tem por objetivo apresentar uma avaliação da luz em tais edifícios. Começamos com o conhecimento do lugar e suas características ambientais relacionadas com a luz natural de Brasília. Em seguida, discutimos a reabilitação a partir de uma perspectiva bioclimática uma vez que a configuração do relevo e a visão de um horizonte de $360^{\circ}$ e da abóbada celeste influenciam fortemente o procedimento projetual no Planalto.

\section{A PAISAGEM COMO PREMISSA FUNDAMENTAL}

A cidade de Brasília, no seu planejamento inicial, soube acomodar seu desenho ao sitio e recriar as características especiais deste, com a valorização das perspectivas, a introdução do elemento que faltava - a água - e o descortinar da paisagem sobre o lago e a chapada do Paranoá. A configuração urbana de Brasília lhe garante uma excepcional qualidade de orientabilidade que se apóia em princípios "cósmicos" de localização no espaço. Essa orientabilidade fica evidente na localização dos lugares e objetos em relação aos eixos abstratos que arquetipicamente estruturam a abóbada celeste e definem os quatro pontos cardeais: norte, sul, leste e oeste.

Oque dá ao "homem de Brasília" a sensação de segurança no lugar e no domínio visual sobre a paisagem (céu e terra) é a sua legibilidade ou facilidade de compreensão decorrente de relações espaciais claras entre os seus elementos. No vocabulário de Norberg Schulz, estas características situam Brasília, enquanto lugar, entre os domínios do cósmico e do clássico, e são essenciais na definição do seu genius loci. (ver Romero, 2001)

Nesse sentido destaca-se o cuidadoso trabalho de Lúcio Costa, que realiza uma acertada leitura do sítio, acomodando seu projeto à forma daquele. É assim que ele estabelece um vínculo com o espaço e escolhe para a localização da cidade o triângulo contido entre os braços do lago.

Em Brasília, a "muralha" das chapadas constitui ao mesmo tempo um horizonte e um fechamento. Esta dupla função talvez constitua o mais importante elemento definidor da relação entre o céu e a terra no sitio de Brasília. O significado dessa estrutura espacial para o caráter do lugar diz que no sitio que recebeu Brasília, o mundo protege o homem, ao mesmo tempo 
em que lhe revela sua ordem cósmica.

A configuração do relevo, que define sua paisagem, garante a Brasília à visão de um horizonte de $360^{\circ}$ e da abóbada celeste como um semi-hemisfério completo. A vista alcança grandes extensões e a paisagem se espraia em cerrados distantes. Do ponto de vista da ocupação urbana, para Lúcio Costa, a construção da identidade da paisagem cultural na bacia do lago Paranoá deve levar em consideração a "vista desimpedida sobre a paisagem", para que se mantenha "a serenidade da linha do horizonte". Esta disposição influencia fortemente $\mathrm{o}$ procedimento projetual no Planalto. A proteção e dosagem da intensidade da luz do sol e da excessiva luminância da abobada celeste, associadas à composição plástica do edifício, integram o vocabulário de composição brasiliense.

$\mathrm{Na}$ estrutura da paisagem, o céu tem papel fundamental. A abóbada celeste é percebida quase como uma calota completa. Aolongo do dia, a variação da luz é absolutamente marcante durante o pôr e o nascer do sol, principalmente nas épocas de céu parcialmente nublado, em que as nuvens se tingem de tons absolutamente surpreendentes que transformam não só a região da abóbada celeste em torno do disco solar, mas toda a paisagem. O céu é também o cenário de outros fenômenos importantes para o "habitar" no Planalto Central: o nascer da lua cheia, as nuvens de chuva e as tempestades vistas a grandes distancias, o arco cintilante da Via Láctea nas noites sem nuvens.

Habitar no Planalto é estar em constante contato com o céu e em contemplação do horizonte e da paisagem, em que a vista alcança grandes distâncias. A paisagem não significa algo dominado e controlado, ou algo desumanamente poderoso, mas uma manifestação cósmica capaz de oferecer abrigo à vida cotidiana, sinalizando ao mesmo tempo a sua transcendência.

Mascaró (1981, 47) lembra que a disponibilidade de luz natural, ligada às características da abobada celeste do lugar, caracteriza a fonte de luz natural no tocante à variação e potência, levando em conta a latitude e a nebulosidade local. Essas características estão intimamente associadas à pluviosidade (presença de nuvens), trajetórias diária e anual do sol (produzindo uma determinada radiação termo-luminosa) e aos ventos dominantes (que entre outras funções, ajudarão a manter limpo ou não o céu).

A divisão rítmica do tempo entre uma estação de seca e uma época de chuva é elemento fundamental de estruturação do lugar. Na seca, o cerrado se torna uma paisagem árida, e aumenta o contraste entre o verde escuro das matas de galeria e as cores amareladas dos campos e cerrados ressequidos. O céu absolutamente livre de nuvens, se torna cinzento e estagnado. Na época das chuvas, o céu varia de azul brilhante a inteiramente coberto por nuvens baixas de chuva e a vegetação recupera o viço e o verde.

O brasiliense tem uma relação muito intensa com a luz. Na época da seca, as partículas de poeira dissipam a luz, e ao espalhar os raios de sol fazem com que a gente perceba mais tons de vermelho, laranja e amarelo. Na seca a inclinação dos raios solares é maior o que espalha ainda mais as ondas mais compridas. $\mathrm{Na}$ cidade feita de horizontes o por do sol fica avermelhado. Vale lembrar que basta a umidade do ar atingir índices mínimos em agosto e setembro para que as arvores do cerrado exibam suas flores, numa medida de proteção contra a baixa umidade (para diminuir a área de transpiração e perder menos água) perdem as folhas, destacando contra o azul do céu, o Ipê, por exemplo, suas flores amarelas, brancas e rosas.

O Lago Paranoá estabelece uma fronteira para a área urbana e contribui para a disponibilidade de luz a partir das suas reflexões. Se, por um lado, sua superfície reflexiva tem um efeito desmaterializador, que se contrapõe à estável estrutura topográfica, por outro, a perenidade de suas águas e seu contorno imutável são signos de estabilidade e permanência que se contrapõem, respectivamente, à sazonalidade das chuvas e à constante transformação da paisagem em processo ininterrupto de urbanização (ROMERO, 
2006b). Pode-se dizer ainda do lago Paranoá que suas águas oferecem reflexos mágicos da aurora, do crepúsculo e da lua cheia, multiplicando o impacto visual destes fenômenos tão, caros ao habitante de Brasília. Em Brasília existe a experiência diária, quase tangível, de testemunhar pela manhã ao nascer o sol atrás de um horizonte visível, acompanhar seu trajeto ao longo da abóbada celeste e seu crepúsculo ao final do dia.

A conservação dos rasgos naturais da paisagem permite que exista senso do lugar e sensibilidade para o contexto; a escala percebida é mais continua e complexa. Um alto grau de sensibilidade ecológica permite a criação de zona de transição entre o ambiente natural e o artificial (ROMERO, 2006a). Assim, é mantido o grau máximo de diversidade, aproveitando, para tanto, as condições específicas de cada lugar. Isso nos leva a concluir que a premissa bioclimática fundamental é que o sítio, a paisagem e as formas naturais do terreno constituem as bases de projeto.

A iluminação resulta então, tanto de recursos pré-determinados em projeto como de efeitos variáveis e imprevisíveis surgidos face à natureza inconstante e indisciplinada da luz na arquitetura.

\section{REABILITAÇÃO MAIS ATENTA AOS LUGARES}

Num processo de legitimação do conceito de sustentabilidade, que procura diminuir significativamente a pressão sobre os recursos disponíveis e a ampliação da responsabilidade ecológica, pensar na reabilitação requer, em primeiro lugar, aceitar que o conceito abrange ações de reimplementação ${ }^{2}$ de antigas funções. Reabilitação abrange, portanto, a reutilização do patrimônio existente, a alteração nos padrões de consumo, o incremento da eficiência energética, a adaptação aos avanços tecnológicos e a preocupação com as possibilidades de otimização dos espaços.

Nas ações de reabilitação é essencial a introdução da vitalidade, cujo intuito é sustentar as funções vitais da população e o ajustamento entre o espaço urbano construído e a capacidade sensorial dos habitantes do lugar. Também uma adequação atenta à acessibilidade deve ser observada.

O conceito de reabilitação, no entanto, está menos ligado à idéia de perda anterior de vitalidade e traz mais clara a idéia de acréscimo de atividades geradoras de ganhos econômicos e de melhoria da qualidade dos espaços públicos e privados, podendo ser melhor aplicado em situações cujo objetivoéa alteração das características físicas e da composição social e econômica de áreas ainda ocupadas. Envolvendo processos de elitização ("gentrification"), a reabilitação está principalmente voltada para o estabelecimento de novos padrões de organização e utilização dos espaços, com vistas a uma melhoria significativa da qualidade de vida.

Em paises com espaços construídos muito consolidados pela passagem do tempo, as preocupações com a recuperação do existente são constantes, guiadas muitas vezes, pela necessidade de tornar habitável um entorno degradado e perigoso. A reabilitação do existente visa na maioria das vezes, substituir os velhos ambientes com grande desperdício de energias por novas formas de baixo consumo energético e, além disso, utilizar a opção de ocupar os espaços intersticiais entre as edificações.

\section{A INTEGRAÇÃO DOS ASPECTOS CLIMÁTICOS, CULTURAIS E HISTÓRICOS: BIOCLIMATISMO}

Os termos bioclimático ou sustentável passaram a ser amplamente utilizados na última década e também no contexto de concursos internacionais de grande envergadura. Algumas vezes seu uso se limitava a apenas uma adjetivação de uma arquitetura que se diferenciava de outras que não considerassem os aspectos bioclimáticos. Entretanto, ao historiar o termo, SERRA (1998) aponta que Olgyay, que o cunhou, referia-se especificamente a uma interpretação bioclimática da 
arquitetura, o que significava que os elementos bioclimáticos deveriam estar presentes em toda arquitetura qualificando o projeto, não apenas diferenciando. Tratase, em outras palavras, de uma arquitetura na qual, independentemente da linguagem arquitetônica utilizada, estaria presente o comprometimento com a sustentabilidade do planeta e da sociedade humana.

Consideramos que o Bioclimatismo representa dealgumaforma, uma superação e, como uma etapa atual do movimento climático-energético, a conceituamos, então, como uma forma lógica de desenho que reconhece a persistência do existente, culturalmente adequada ao lugar e aos materiais locais e que utiliza a própria concepção arquitetural como mediadora entre o homem e o meio. Por tal motivo, adotamos seus princípios para fazer a análise do desempenho das constantes morfológicas.

Os elementos de desenho bioclimático compreendemoselementos condicionantes do ambiente por um lado e, os elementos condicionantes do espaço analisado por outro, criando assim os parâmetros de desenho ambiental integrado para os espaços construídos.

Essas características constroem a processualidade do Bioclimatismo e demandam metodologia de aplicação muito flexível. Métodos e procedimentos para obter soluções bioclimáticas devem reger-se pela integração e interação dos aspectos climáticos, históricos e culturais em suas diversas etapas, e tais etapas devem retroalimentar-se continuamente. Substitui-se, assim, o modelo tradicional analítico, atomizado e temporalmente estático, por atividades com revisão periódica e adaptação às características da realidade.

GIVONI (1998) lista algumas formas de interação entre o edifício e o ambiente: a efetiva exposição solar dos elementos opacos e transparentes das envoltórias dos edifícios, o efetivo ganho de calor solar dos edifícios, a razão entre o ganho e a perda de calor do ar ambiente e o potencial de ventilação natural e refrigeração passiva do edifício. Assim sendo, as variáveis de projeto de maior relevância, que interferem nas interações acima, são: (i) a forma do edifício: (ii) a orientação, condições de sombreamento e penetração da luz pelas aberturas; (iii) a dimensão e localização das aberturas em relação às condições de ventilação e iluminação; (iv) as características térmicas dos materiais de construção quanto aos ganhos e perdas de calor; (v) a orientação e cor dos fechamentos opacos; (vi), a ventilação interna considerando-se seu efeito na temperatura interna do edifício e (vii) o revestimento da área de entorno do edifício e paisagismo.

As quatro primeiras variáveis estão diretamente relacionadas à proteção solar e iluminação natural, sendo que algumas delas podem agir combinadamente, intensificando o efeito desejado enquanto outras poderão agir em oposição. Daí a necessidade de o arquiteto avaliar cuidadosamente como contornar as dificuldades e escolher aquelas que melhor se integram para um resultado final satisfatório num projeto que explore a luz como estratégia de reabilitação, isto é, que se traduza em condições de maior conforto para os ocupantes, menor consumo de energia e menor impacto no meio ambiente resultando em maior sustentabilidade.

\section{DA TRANSPARÊNCIA-CLARIDADE, OPACIDADE-PENUMBRA E OS PEQUENOS CONTRASTES DA LUZ}

A luz é o componente fundamental do olhar. A luz orienta, destaca, esconde, transforma, integra, isola. O complemento da luz, a sombra, trabalha em sintonia, para melhor sublinhar ou esconder, para melhor descobrir ou dissimular. A luz destaca, quer dizer, leva em conta a singularidade de cada cidade, de cada bairro, de cada edifício, assim como a sua história, sua morfologia, sua personalidade, com vistas a criar uma silhueta diurna e noturna original e inovadora, buscando a interação dos espaços iluminados com o entorno próximo ou distante. 
A qualidade da luz no espaço é mais importante do que sua quantidade para a criação dos efeitos plásticos desejados. Por exemplo, uma brilhante luz diurna incidindo diretamente sobre uma superfície projetará um mínimo de sombra e, portanto, um mínimo de efeito plástico; o efeito da textura será também pobre, simplesmente porque a percepção da textura depende de pequenas diferenças de relevo e a luz brilhante de incidência direta não cria as condições para a apresentação de matizes que façam insinuações com as áreas sombreadas (ROMERO, 2001).

Conhecendo o nível das luminâncias, o direcionamento da luz, pode-se trabalhar com o que é chamado "estética da luz" e, com isso, é possível criar vários efeitos, entre os quais destacamos: o ritmo, a ênfase e o contraste ${ }^{3}$. O efeito texturial não será de grande riqueza, porque a percepção da textura depende de pequenas diferenças de relevo, e o relevo, nesse caso, estaria destacado pela iluminação. Se as partes iluminadas são muito claras, a forma neste lado é opaca, e a parte em sombras, muito escura; portanto, não se verão formas; o excesso de luz faz com que as superfícies pareçam planas e com péssima qualidade.

A luz, já denominada como ajudante silencioso, não pode ter sua importância protagônica diminuída duranteo dia. Nesse período, é importante também levar em conta aspectos conseqüentes da presença daqueles elementos que produzem a luz da noite, tais como: desenho das luminárias, significado simbólico, etc, próprios da iluminação pública. Em geral encontramos essa preocupação de inclusão dos elementos de iluminação durante o dia nos espaços de reabilitação recentes, uma vez que, ao trabalhar com sombras projetadas no solo (onde parecem exageradas), estas se convertem em arquitetura.

Também é importante levar em conta que os reflexos brilhantes dão às cores uma riqueza especial. Então, deve existir um cuidado especial para que haja uma quantidade conveniente de luz refletida na sombra para obter relevo. No fenômeno da sombra atua o reflexo ilusório da realidade, a desmaterialização do sólido, do concreto; gera-se ali um dispositivo de desdobramento despersonalizado. Destacamos a sombra produzida pela vegetação que, ao filtrar a intensa luz que a atravessa (nas latitudes próximas do Equador, a exemplo de Brasília), ameniza decididamentea sensaçãotérmicae destaca, pelo contraste, as cores intensas da floração da seca. A luminosidade de Brasília mudou a pintura de Glênio Bianchetti, lembra-nos hoje Nahima Maciel no artigo do Correio Braziliense de 08/04/2007, para quem, "a luz européia de Rio Grande do Sul natal estimulava tonalidades marrom. No Planalto Central as cores brotaram".

Em Brasília o uso de grandes áreas de superfície envidraçadas, uma das características marcantes da arquitetura do movimento moderno, está presente nos edifícios de envoltório transparente, das décadas de 50 e 60 . Ao mesmo tempo a luz tem sua intensidade controlada por dispositivos de proteção solar que funcionam também como elementos difusores e condutores. Essa característica foi deixada de lado nas edificações recentes da cidade, nas quais foi introduzido o vidro reflexivo sem levar em conta a alteração na ambiência que produziria.

Princípios de repetição e modulação de elementos arquitetônicos relacionados à luz, tais como brises, colunas, pilares e aberturas, geram um ritmo na modulação da luz, variável no decorrer do tempo. Os protetores solares constituem para SERRA \& COCH (2000) um conjunto de componentes destinados a proteger a pele dos edifícios ou de espaços externos conectados ao ambiente interno, contra o excesso de radiação solar, indesejáveis nos períodos quentes.

O estudo das questões teóricas, técnicas e práticas da proteção solar evidenciam as possibilidades compositivas dos brise-soleils. OLGYAY \& OLGYAY (1957) consideram que eles oferecem possibilidades enriquecedoras para a expressão visual. Se alguns servem apenas para tratar a superfície, outros participam do jogo de luzes e sombras, criam efeitos espaciais e podem assumir, como elementos 
arquitetônicos, valores formais diversos, participando na definição plástica, além das questões evidentes de proteção solar.

Nos climas quentes ou nas épocas de calor dos climas temperados, a proteção solar é muito mais importante que o isolamento térmico em relação ao sobre-aquecimento dos interiores. Para atender os requisitos bioclimáticos, o protetor solar deve, além da função principal, permitir a ventilação dos espaços interiores, a visão do exterior e criar uma certa iluminação difusa nos espaços habitáveis. PARICIO (1997), ao analisar os motivos principalmente simbólicos que tornam a arquitetura da cortina de vidro tão presente, mesmo em lugares de clima quente, ressalta que algumas arquiteturas contemporâneas, ao tentar alcançar imagens de transparência e leveza, têm exagerado no tamanho das superfícies envidraçadas e desprotegidas, chegando a extremos insuportáveis para os climas quentes. Afirma que a presença da proteção solar incide substancialmente na forma da arquitetura, podendo resultar em imagens arquitetônicas radicalmente diversas dependendo do caminho adotado.

Recursos de harmonia ${ }^{4}$ e ritmo são os mais encontrados na iluminação dos edifícios em Brasília. Verificamos também duas formas de trabalhar a luz, em função do tratamento do envoltório: transparênciaclaridade e opacidade-penumbra. Apesar da predominância deste efeito, também são encontrados pequenos contrastes, entre espaços mais ou menos iluminados, acentuados pelo tratamento dos revestimentos.

Em ambas as modalidades de trabalho com a luz, há predominância do uso de iluminação lateral distribuída de forma heterogênea; as paredes brancas, de ampla utilização na cidade, auxiliam nesta tarefa. Ailuminaçãodos espaçosinterioresutiliza a luz da abobada celeste como principal fonte luminosa. Os procedimentos projetuais encontrados buscam a qualificação da arquitetura, integrando aspectos plásticos e uso. As regras desta integração são observadas de forma a ultrapassar a simples necessidade de conforto luminoso onde a dimensão plástica, a dimensão estética, de conformação tátil dos espaços impõem soluções além das estritamente técnicas.

Às vezes a claridade é substituída pela penumbra acentuada pelos revestimentos dos ambientes interiores, sendo também recorrente a adoção de espaços semi enterrados. As reflexões obtidas nos azulejos são amplamente aproveitadas na cidade; seguindo a tradição do mestre Athos Bulcão, o azulejo como revestimento é encontrado em todo tipo de edificações. Também verifica-se a iluminação pontual, através de pequenas aberturas, na maioria das vezes tratadas como vitrais. Estas, ao pontuar de claridade os espaços em penumbra, produzem uma iluminação de ênfase e de contrastes, enfatizando ora o objeto, ora o espaço iluminado.

\section{SOBRE OS EDIFÍCIOS OBJETO DA AVALIAÇÃO}

A avaliação ambiental integrada realizada em edifícios complexos do campus da UNB se fundamentou numa análise ambiental integrada bioclimática, para a qual utilizamos o método de Romero (2001). A avaliação considerou algumas diretrizes quanto ao caráter do edifício e às características do lugar ${ }^{5}$, tratando-os como objetos arquitetônicos que geram, com seu uso, contextos sociais, econômicos e ambientais diversos.

Foi aplicada uma avaliação ambiental integrada (ROMERO, 2001) no edifício que abriga a maior quantidade de unidades acadêmicas do Campus da UNB, o Instituto Central de Ciências - ICC, realizada, em um primeiro momento, a partir de uma análise sensorial, organizada em checklist, contendo categorias e subcategorias de desempenho a serem estudadas, tais como: conforto térmico, luminoso e acústico. Em um segundo momento foram relacionados os atributos espaciais com as condições de desempenho ambiental às quais foram atribuídos valores de adequabilidade. Dessa forma, são definidos indicadores do ambiente construído relacionados diretamentecomresultadosdedesempenho 
ambiental, diferenciados conforme os diferentes usos, necessidades, condições climáticas locais e as características do projeto arquitetônico, dada sua grande diversidade mórfica. Finalmente os indicadores são avaliados pelo enfoque da sustentabilidade.

\section{Instituto Central de Ciências - ICC}

O edifício Instituto Central de Ciências ICC, de concepção arrojada e monumental, apresenta condições físico-ambientais bastante diversificadas conforme seus três pavimentos, blocos, alas e orientações. As adaptações aos usos por que tem passado ao longo de seus mais de quarenta anos de existência, aumentaram ainda mais a diversidade de suas condições ambientais. Atualmente seus usuários demonstram uma insatisfação geral em relação a essas condições, o que gerou a necessidade de um trabalho de readequação ambiental ${ }^{6}$.

Dado o fato do ICC já fazer parte do imaginário da grande maioria da população do Distrito Federal, seja porque acolheu a população como estudante, servidor, manifestante, em variadas décadas da vida da cidade, ele sempre mereceu cuidados e atenções especiais. Reações diversas ocorrem frente a essa situação, desde o gradeamento para conter a violência do lado de fora do edifício até a demarcação de territorialidades internas. Tais fatos fazem do edifício um "território livre" para as mais variadas intervenções visando à acomodação das unidades acadêmicas, finalidade para a qual foi criado e também como não poderia deixar de ser, às mais variadas manifestações culturais.

O trabalho de reabilitação do ICC foi dividido em quatro etapas:

planejamento, que envolveu três tipos de análise: levantamento e definição de espaços típicos, análise sensorial e a avaliação e definição de indicadores de desempenho ambiental;

verificação, etapa em que foram realizadas medições e simulações;

elaboração de diagnóstico, com bases nos resultados das etapas de planejamento e verificação

e elaboração de diretrizes, a etapa final, que envolvia a elaboração de projeto para a adequação dos ambientes típicos.

\section{Quanto à forma do edifício}

Fruto de uma concepção audaciosa, o ICC possui alguns espaços extremamente agradáveis e, apesar de suas dimensões imensas, surpreende pela discrição de sua presença na paisagem. O edifício é compreendido como um grande bloco composto de duas alas paralelas, com pátio central em toda a extensão dos seus 720 metros. As duas alas são ligadas entre si por alamedas transversais e praças, que entrecortam o jardim ao longo de todo o bloco central. Cada ala, de larguras diferentes, foi concebida para destinações distintas: a mais larga de $30 \mathrm{~m}$, com parte em pé direito duplo para laboratórios de pesquisa; e a mais estreita de $25 \mathrm{~m}$, provida de anfiteatros e salas de aula de capacidade variável, servindo principalmente a atividades de ensino. $\mathrm{O}$ volume no sentido longitudinal é formado por dois blocos unidos por uma área originalmente proposta para abrigar laboratórios.

As alas norte e sul compõem os segmentos retos do edifício, enquanto a parte intermediária é um trecho curvo que acompanha de maneira natural a topografia do sitio. Aconcordância, entre os segmentos retos e curvos intermediários é marcada pelos halls centrais de distribuição e pelos grandes mezaninos que ligam as duas alas no primeiro nível do piso. Uma rua interna percorre o bloco em toda a extensão, sob a ala dos laboratórios. A área livre entre as alas, também se destina a laboratórios, cuja cobertura se apóia nas paredes longitudinais das mesmas, na altura e forma solicitadas.

Os recursos relacionados com a proteção solar, no que se refere aos efeitos termoluminososdosol, tradicionaisdaarquitetura colonial, são reinterpretadas e aparecem nos largos corredores. Ao mesmo tempo em que atendem às exigências climáticas, 
conferem a monumentalidade requerida.

A fachada leste voltada para o lago Paranoá é predominantemente envidraçada, ao contrario da fachada oeste com aberturas mais reduzidas. Nas faces externas leste e oeste há brises verticais móveis em toda sua extensão.

\section{Zoneamento Bioclimático}

Foi elaborado um zoneamento bioclimático (ver figuras 1,2, e 3), com base em uma serie de estratégias bioclimáticas ${ }^{7}$ previamente elaboradas pela equipe, para as diversas alas, pisos e blocos do ICC. Estas estratégias levam em consideração os elementos que devem ser priorizados, em especial os que privilegiam a utilização de luz natural, para uma ocupação adequada das unidades acadêmicas que ai encontram abrigo. Estas diretrizes foram elaboradas para o que se denominou a ossatura e a pele do edifício, sem levar em conta a atual distribuição de atividades nem as futuras. Adotou-se este procedimento para cada bloco, como segue a continuação, para preservar o caráter geral da proposta.

Subsolo:BlocoA;Faixacontinentalnolimite da rua de serviço, com condicionamento artificial quando a carga térmica o solicite (ar condicionado) ou ventilação natural por dutos resfriados. Faixa com resfriamento evaporativo, jardim com ventilação permanente na orientação Leste. Taludes. Bloco B; Faixa continental no limite do corredor de serviço, com condicionamento artificial quando a carga térmica o solicite (ar condicionado) ou ventilação natural com captadores de vento. Faixa com resfriamento evaporativo, jardim com ventilação permanente na orientação Oeste. Iluminação e ventilação natural. Bloco C; Faixa mediterrânea com jardins de resfriamento evaporativo. Filtros vegetais do ar poluído da rua de serviço. Prateleiras de luz. Brises. Ventilação cruzada. Inércia térmica. Fig.1

Térreo: Bloco A; Faixa com resfriamento evaporativo, linha de arvores de 6 a 8 metros da face leste, proporcionando sombra e ar resfriado pela vegetação. Bloqueio da radiação solar direta no lado mediterrâneo com trepadeiras guiadas com protetores solares. Brises. WWR. Bloco B; Faixa com resfriamento evaporativo, linha de arvores de 6 a 8 metros da face oeste, proporcionando sombra e ar resfriado pela vegetação. Barreira vegetal no lado do estacionamento, filtro de poluição e desvio do ruído, amenizar. Bloqueio da radiação solar direta no lado mediterrâneo com trepadeiras guiadas com protetores solares. WWR. Bloco C; Pergolados ou coberturas leves para os Jardins com mesas para convívio e lanches. Fig.2

Mezanino: Bloco A; Faixa com resfriamento evaporativo, linha de arvores de 6 a 8 metros da face leste, proporcionando sombra e ar resfriado pela vegetação. Bloqueio da radiação solar direta no lado mediterrâneo com trepadeiras guiadas com protetores solares. Brises. WWR. Bloco B; Proteção da radiação direta. Bloqueio da radiação solar direta no lado mediterrâneo com trepadeiras guiadas com protetores solares. Brises. WWR. Fig.3 


\section{Zoneamento de estratégias bioclimáticas}

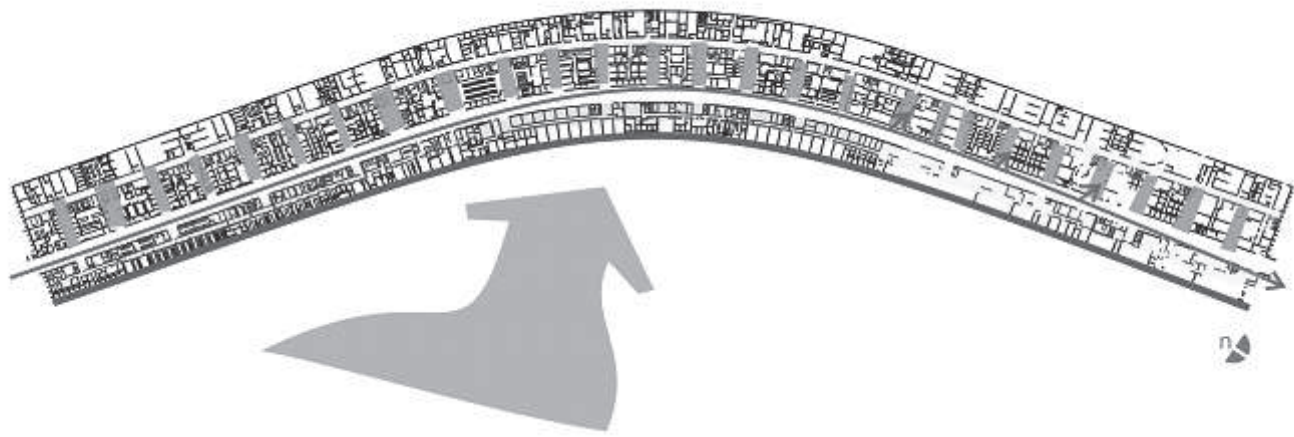

faixa mediterrånea

a natural forisa/pratoi

aixa resfriamento evaporativo

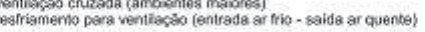

faixa continental (com radiaçăo direta) ar condicichado

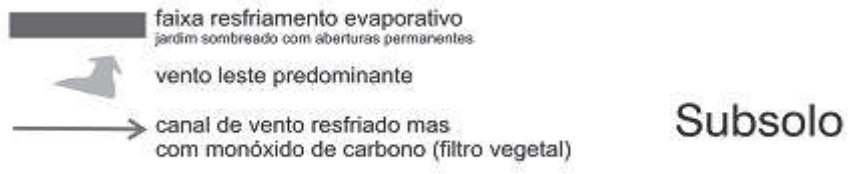

Figura 1: Zoneamento de estratégias bioclimáticas para o pavimento subsolo.

\section{Zoneamento de estratégias bioclimáticas}

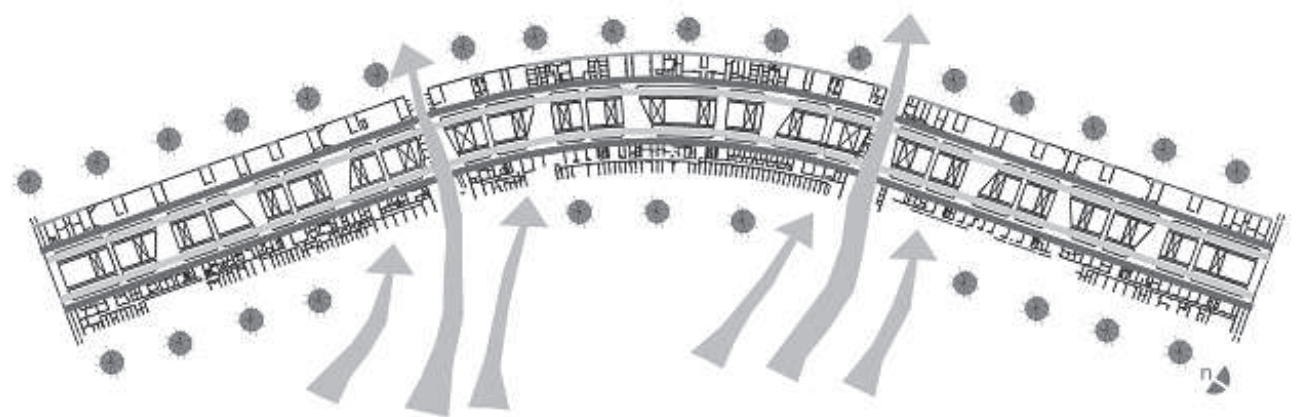

aberturas transparentes com proteçāo

hloquear radiçăo solar com vegetaçăo (trepadeiras) com suporte de delimitaçáo de áreas

faixas continental com radiaça direta/A=tarde e $\mathrm{B}=$ manhà

arborizaçăo externa - espaçamento 16 de eixo / espécies: Pequi e Flor-de-macaco

vento leste predominante

Térreo

Figura 2: Zoneamento de estratégias bioclimáticas para o pavimento térreo. 


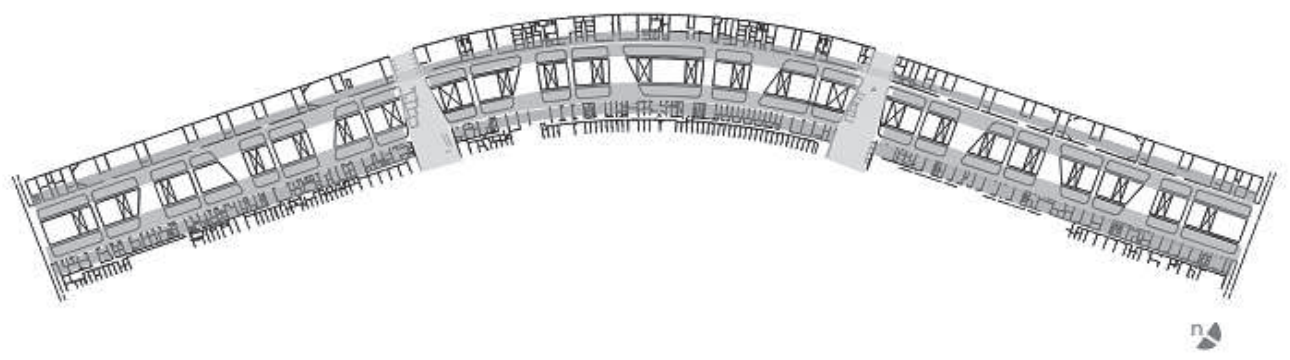

cobertura para convivio

bloquear radiação solar com vegetação (trepadeira com suporte de delimitação de área)

luz difusa no caixilho com peitoril de $(1,0 \mathrm{~m})$

segurança e ventilaçāo

Sobreloja

Figura 3: Zoneamento de estratégias bioclimáticas para o pavimento mezanino.

\section{Sobre o desempenho da iluminação natural no ICC}

Verificou-se baixa uniformidade da luz natural (Uo), principalmente nos ambientes que desfrutam da iluminação natural, localizados no térreo e mezanino. Nestes mesmos ambientes, há incidência excessiva de radiação direta (acima de 2000 lux) e alguns pontos com iluminâncias abaixo de 100 lux, o que comprova a má distribuição da luz natural; no caso, a incidência de radiação direta irá provocar aumento de temperatura e problemas de conforto visual, como ofuscamento e reflexos.

Quanto à iluminação artificial, apresenta-se insuficiente em alguns casos (média abaixo de 300 lux) e excessiva em outros; também não há nenhuma relação entre o projeto de iluminação artificial e o comportamento da luz natural, o que seria desejável para se atingir a eficiência energética.

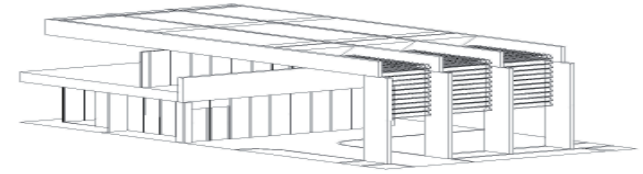

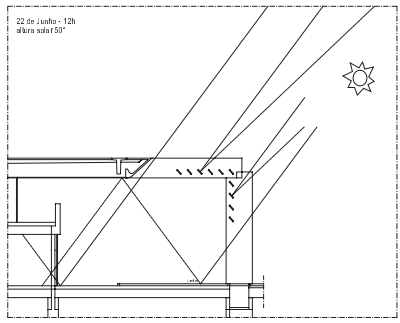

Figura 4: Protetores semi-opacos - pergolado para vegetação.

Fonte: Relatório Adequação Ambiental, Ceplan, 2005.

\section{Faculdade de Tecnologia - FT}

A FT apresenta uma forte caracterização espacial, identificada através da definição de seus blocos; o edifício encontra-se em bom estado de conservação, resultando num conjunto cujo de ambientes decididamente agradáveis. A ambiência externa contrasta com a interna, onde a proliferação de equipamentos e elementos como ar condicionado, grades, infiltrações, e luminosidade excessiva, antecipa a inadequação ambiental do espaço, assim como gera o consumo excessivo derecursos. Os espaços entre os blocos são pouco definidos funcionalmente, ou inadequados para as necessidades ambientais e sociais. 
A presença de árvores é marcada pela casualidade: gêneros arbóreos diversos estão colocados como elementos residuais ou intersticiais e não de forma integrada a outras categorias de serviços ou como uma resposta adequada à uma série de necessidades ambientais quotidianas. Faz parte também da FT os Blocos de serviços gerais que apresentam uma arquitetura semelhante as dos grandes galpões fechados.

$\mathrm{Na}$ avaliação da $\mathrm{FT}^{8}$, adaptamos a metodologia utilizada no ICC para dar inicio ao processo de reabilitação. Assim, inicialmente, na Etapa de Planejamento decidimos fazer uma análise por amostragem e escolhemos para tanto, quatro ambientes do edifício principal, dois ambientes no pavimento térreo e dois ambientes no pavimento superior, cuidando para que a seleção abrangesse as principais orientações e exposições do edifício. Escolhemos também sete ambientes do Bloco de Serviços Gerais SG 12 como amostras dos edifícios desse formato e denominação. $\mathrm{Na}$ etapa de verificação incluímos a análise sensorial, com fichas adaptadas com a atribuição de indicadores, e realizamos medições e simulações dos ambientes do edifício principal da FT e somente análise sensorial e simulações do SG 12 . Na etapa Recomendações realizamos diagnósticos e apontamos soluções sustentáveis para os problemas de desempenho ambiental encontrados.

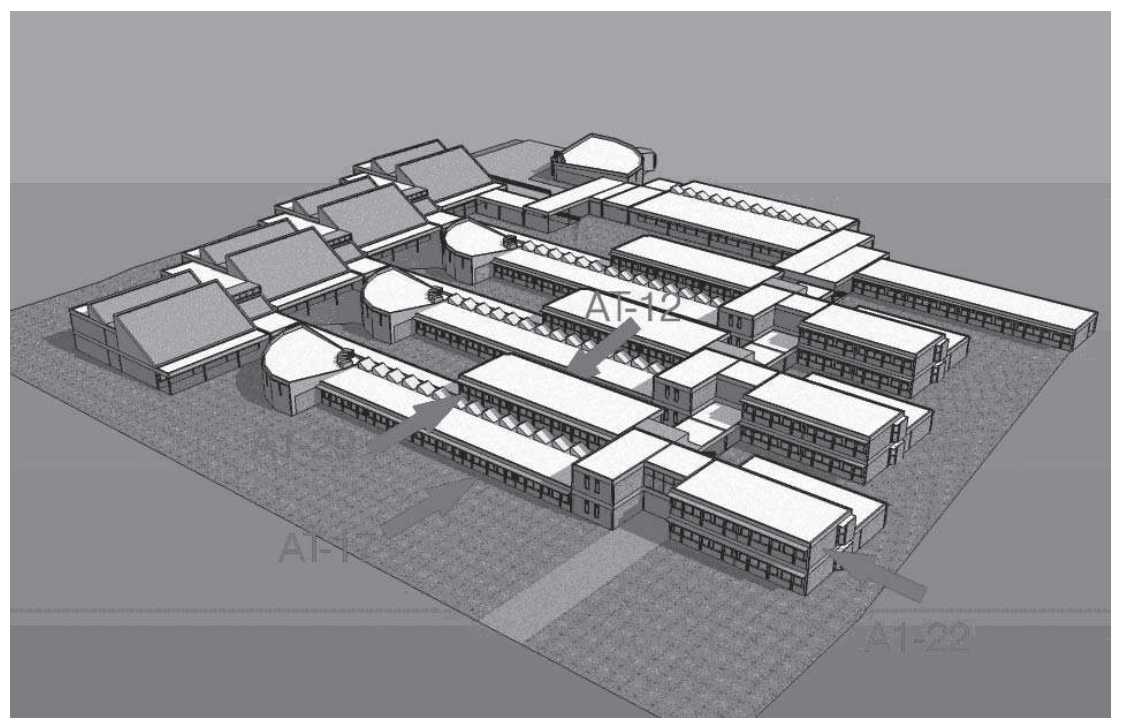

Fig. 5.- Ambientes analisados na FT

Sobre o desempenho da iluminação natural na FT

A distância entre os blocos projeta sombra (pela proximidade e pela altura); os ambientes localizados no lado Oeste se apresentam com baixo nível de iluminância em toda a sua extensão, devido à sua localização, pois ao seu lado, próximo à abertura, ou no lado próximo à abertura encontra-se um outro bloco de edifício num nível um pouco acima deste. A configuração da abertura prejudica uma distribuição mais uniforme e eficiente da iluminação natural, pois sua localização num lado extremo da sala prioriza a entrada da luz apenas nesse local. Isto acaba gerando a incidência de raios solares diretos e a ocorrência de ofuscamento. Para solucionar esta situação, propusemos que a configuração da abertura lateral adotasse um formato alongado (no sentido horizontal) abrangendo toda a extensão do ambiente, com peitoril de altura acima da superfície de trabalho.

Existe alta incidência de radiação solar direta no período matutino, principalmente na área próxima à abertura, acarretando possibilidade de ocorrência de ofuscamento, excesso de brilho sobre as superfícies de trabalho (carteiras) e de contrastes marcantes. Nos demais horários, o nível de iluminância é constante, porém 
com valores abaixo da média estipulada9. A existência de abertura zenital tipo shed na cobertura no sentido oposto ao da abertura lateral não demonstrou níveis de iluminância significativos no período em que foram realizadas as medições, pois a abóbada celeste encontrava-se, nesses dias, parcialmente encoberta. Entretanto, nas medições realizadas a partir das $14 \mathrm{~h}$ pode-se verificar a presença de certos feixes de luz direta, o que pode vir a ocasionar possibilidade de ofuscamento quando a abóbada celeste encontrar-se desobstruída.

As aberturas de ambientes voltadas para "Nordeste Leste" recebem toda a radiação solar pela manhã, tendo incidência de luz solar direta com altos índices de iluminância, o que acaba gerando a ocorrência de ofuscamento em certos pontos do ambiente. Isto só não é mais grave porque as mesas de trabalho estão localizadas no sentido oposto à esta incidência do feixe de luz. Com a abóbada celeste desobstruída (céu claro) percebe-se uma melhora na distribuição dos níveis de iluminância, entretanto, o índice de uniformidade continua abaixo do parâmetro estipulado, principalmente nos locais mais profundos do ambiente.

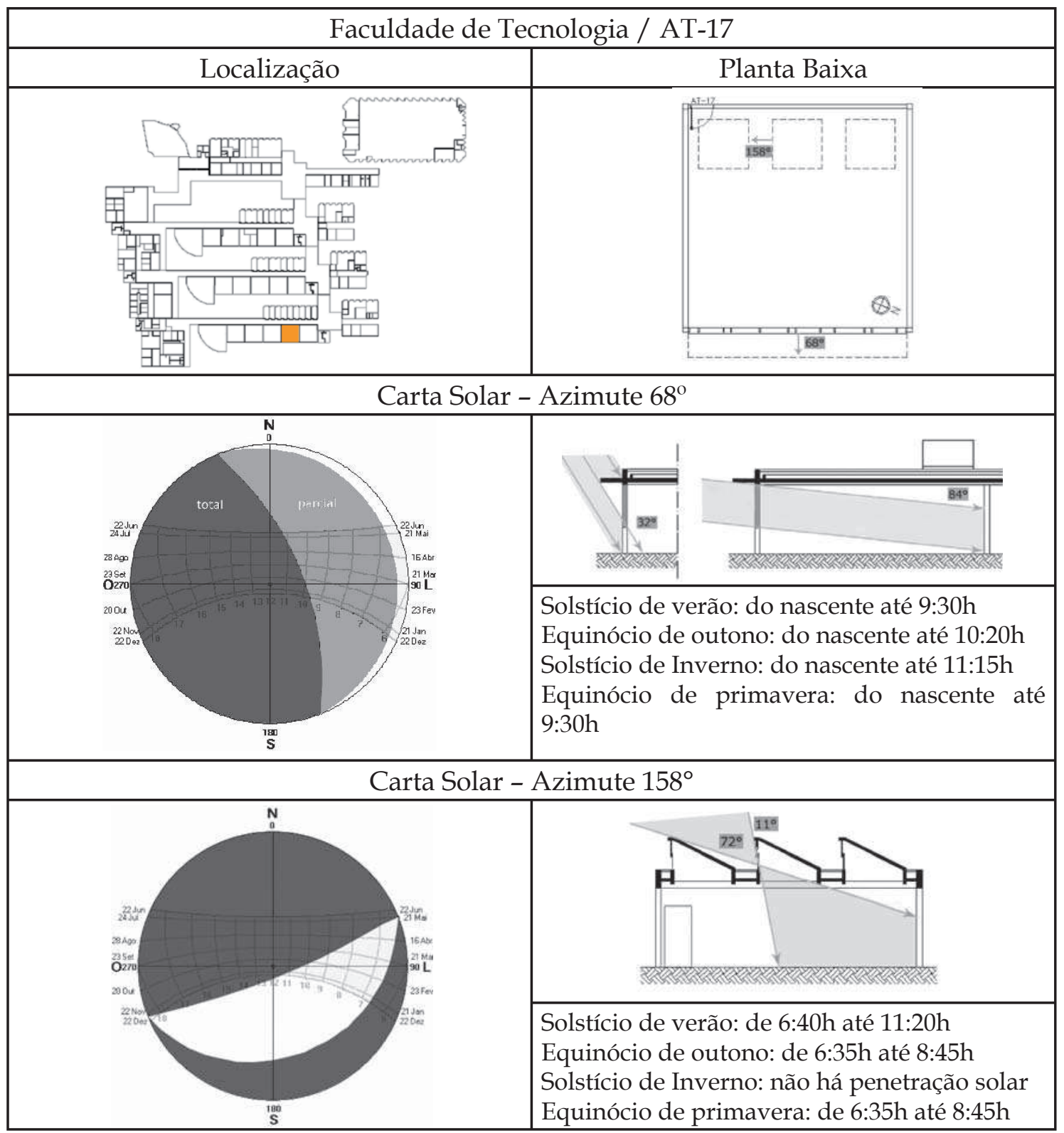

Fig.6.- Exemplo de análise da luz natural - FT 
Os ambientes voltados para "Sudoeste Oeste", no período matutino apresentam os menores índices de iluminância, porém a configuração das aberturas laterais existentesnoambientedificulta emuitouma distribuição maior e melhor da iluminação. Outro fator prejudicial à otimização da iluminação natural neste ambiente são as tonalidades dos revestimentos de superfície e dos mobiliários, pois em sua maioria são cores escuras que dificultam a reflexão da luz. Através das medições in loco pode-se verificar que a uniformidade de iluminância é praticamente inexistente, tornando-se necessário o uso da iluminação artificial em todos os períodos do dia.

\section{CONSIDERAÇÕES FINAIS}

Levando em conta as características do lugar que abriga à cidade de Brasília, assim como sua especial configuração, em consonância com os princípios da bioclimatismo sustentável foi aplicada uma avaliação ambiental integrada no edifício Instituto Central de Ciências da Universidade de Brasília - ICC e na Faculdade de Tecnologia - FT, visando à reabilitação dos mesmos. Destacamos, para este trabalho, os aspectos relativos à luz, segundo os parâmetros em consideração.

A configuração da luz faz com que apresente um horizonte aberto e uma abóbada luminosa e celeste percebida quase como uma calota completa. Isto quer dizer que, ao longo do dia, a variação da luz é absolutamente marcante durante o pôr e o nascer do sol, principalmente nas épocas de céu parcialmente nublado, em que as nuvens se tingem de tons surpreendentes que transformam não só a região da abóbada celeste em torno do disco solar, mas toda a paisagem.

A avaliação dos edifícios foi realizada, em um primeiro momento, a partir de uma análise sensorial, organizada em checklist, contendo categorias e subcategorias de desempenho tais como: conforto térmico, luminoso e acústico. Em um segundo momento relacionamos os atributos espaciais com as condições de desempenho ambiental às quais foram atribuídos valores de adequabilidade, em especial neste estudo, da utilização da luz natural.

Lembramos que conhecer o nível das luminâncias, o direcionamento da luz, e outras qualidades, permite trabalhar com o que é chamado "estética da luz", que depende tanto da concepção sensorial como do manejo de conceitos como níveis de luminâncias e direção da luz. É possível ainda, maximizar a estética da luz mediante a eleição de uma luz que dê muitas variações - da luz alta brilhante até as sombras mais profundas. A partir de tais variações surge a verdadeira plasticidade de cada forma, dispondo equilibradamente para que haja uma quantidade conveniente de luz refletida na sombra, obtendo-se assim também relevo, manchas de luz e sombras produzidas como elementos de animação.

Os fechamentos transparentes têm a função na arquitetura de permitir a iluminação natural do espaço interno e estabelecer uma relação visual com o externo, mas, muitas vezes, o uso indiscriminado de superfícies transparentes causa um sobre-aquecimento das edificações devido ao ganho excessivo de carga térmica decorrente da incidência da radiação solar. Pensamos que o desenvolvimento e aplicação de novas tecnologias de produção de componentes translúcidos (vidros, sistemas seletivos, sistemas avançados entre outros) que, basicamente, buscam alta transmissão luminosa; baixa transmissão de calor e baixa transmissão de ultravioleta tornamse necessários e devem estar disponíveis para uso otimizado da luz natural em ambientes internos.

Destacamos que a reabilitação requer a proposição de recomendações baseadas e respaldadas no conhecimento da sustentabilidade do ambiente construído, quer dizer recomendações mais atentas aos lugares, procurando elementos de coerência com a paisagem circunstante e com a parte da cidade na qual se intervém. Ela requer, antes de tudo, um conhecimento das diversidades dos lugares a fim de redescobrir e valorizar os melhores componentes encontrados, componentes às vezes paisagísticos, outras 
vezes edificatórios ou ainda, relativos a certa qualidade arquitetônica, às vezes esquecida. Para tanto, recomendamos a utilização da abordagem bioclimática, que otimiza a própria concepção arquitetônica nas relações energéticas com o entorno e o meio ambiente. A arquitetura de reabilitação sustentável, aqui aplicada, caracteriza-se por um esforço de compreensão do lugar onde se insere e de seus condicionantes físicos e climáticos, seus aspectos históricos, sociais, culturais e estéticos, coincidindo amplamente com os princípios da arquitetura bioclimática.

\section{REFERÊNCIAS BIBLIOGRÁFICAS}

CEPLAN.RelatórioAdequaçãoAmbiental do Instituto central de Ciências - ICC, Brasília, UNB, 2005.

GIVONI, Baruch. Climate Considerations in Building and Urban Design. New York: John Wiley, 1998.

LUXÁN,Margarita de. “España sostenible”. Revista Arquitectura Viva No 105, Madrid. p. 30-31. 2005

MASCARÓ Lucia. Luz, Clima e Arquitetura, Edições Técnicas, Porto Alegre, 1981

OLGYAY, Victor. Arquitectura y Clima: manual de diseño bioclimático para arquitectos y urbanistas. Barcelona: Gustavo Gili, 1998.

OLGYAY, Victor \& OLGYAY, Aladar. Solar Control \& Shading Devices. New Jersey: Princeton University Press, 1957.

PARÍCIO, Ignacio. La Protección Solar. Barcelona: Bisagra, 1997.

ROMERO, Marta Bustos. Arquitetura Bioclimática do Espaço Público. Editora UNB, Brasília. 2001

ROMERO, M. O Desafio da Construção de Cidades. Arquitetura e Urbanismo - AU, São Paulo, ano 21, No 142, p. 55-58, jan. 2006a.

ROMERO, Marta Bustos. As Características do lugar e a sustentabilidade de Brasília. P@ranoá - Periódico Eletrônico de Arquitetura e Urbanismo, Brasília, v. 8, 2006b. http://www.unb.br/fau/pos_ graduacao/paranoa

SERRA Florensa, Rafael. "Prefacio a la Edición Española". In: OLGYAY, Victor. Arquitectura y Clima: Manual de Diseño Bioclimático para Arquitectos y Urbanistas. Barcelona: Gustavo Gili, 1998.

SERRA Florensa, Rafael \& COCH Roura, Helena. Arquitectura y Energia Natural, Barcelona: Edicions UPC, 2000.

SOUZA Marcelo Sávio de Araújo. “A luz na arquitetura de Oscar Niemeyer", ensaio. FAU/UNB. 1995.

\section{NOTAS}

${ }^{1}$ Qualquer presença real é intimamente relacionada com um caráter, que é determinado pelo material e a constituição formal do lugar. O caráter é a atmosfera do lugar, um fenômeno totalmente qualitativo que não podemos reduzir à soma de seus elementos constitutivos. O caráter é determinado por fatores como proporções, materiais, cores, estratégias de composição e pela forma como os edifícios se encontram com o céu, a terra e outros edifícios. Quer dizer, com a constituição formal do lugar.

${ }^{2}$ Reabilitar: vtd - restabelecer no estado anterior; restituir à estima pública -Michaellis

Reabilitação - processo integrado de recuperação de uma área urbana que se pretende salvaguardar, implicando o restauro de edifícios e a revitalização do tecido econômico e social, no sentido de tornar a área atrativa e dinâmica com boas condições de habitabilidade.

${ }^{3}$ Ritmo consiste em repetir certos efeitos em certos espaços de tempo; ênfase envolve escolher um elemento e destacá-lo; contraste envolve distinguir os volumes construídos no tempo.

${ }^{4}$ A harmonia relaciona-se à distribuição equilibrada da luz nos espaços, sem, contudo ser homogênea e sem atrativo.

${ }^{5}$ Lugar, considerado desde o ponto de vista das características marcantes que denotam o espírito do lugar.

${ }^{6}$ Realizado pelas arquitetas Marta Bustos Romero (Coordenação), Liza Andrade, Darja Kos Braga, Juliana Garrocho, Cláudia Amorim, Rosana Clímaco e estagiários, e Alberto de Faria pelo Ceplan, 2005

${ }^{7} 1$. Bloquear a radiação solar - no térreo na circulação externa aos auditórios com protetores semi-opacos - trepadeiras com aletas de pré-moldado. Vegetação indicada: Flor-de-são-joão (Pyrostegia venusta), semi-lenhosa regional com flores cor alaranjada; Tumbergia ereta (manto-rei) de flor azul intenso; Thumbergia mysorensis (sapatinho-de-judia) flores amarelas; Thumbergia grandiflor (flor azul). 2. Iluminação Natural - nova vedação vertical: instalar elementos nas janelas para melhorar distribuição (prateleiras de luz, persianas ou venezianas com 
controle diferenciado), localizar aberturas na parte superior, não colocar transparências abaixo do plano de trabalho. 3. Ventilação: aumentar aberturas existentes conciliando com a porcentagem necessária para o conforto luminoso (40\% deWWR - opacidadee transparência, como a marquise protege o mezanino esta proporção pode ser aumentada). 4. Renovação de ar: construir sistema de aberturas tipo veneziana móvel basculante na circulação interna das salas de professores para permitir a retirada do ar quente e ao mesmo tempo possibilitar o fechamento devido aos ruídos externos.

8 Trabalho realizado pela equipe do LaSUS, Arquitetas, Marta Romero, Liza Andrade, Juliana Garrocho, Darja Kos Braga, Valeria Moraes, e os estagiários Andiara Campanhoni e Paulo Avelar, e Alberto Alves de Faria pelo Ceplan. Brasília, 2006.

${ }^{9}$ Os índices de avaliação luminosa utilizados com esse método de trabalho foram Iluminância média $(\overline{\mathrm{E}})$ e Uniformidadeiluminância (Un) Iluminância média (E) é a média aritmética de todos os pontos medidos. O ambiente é considerado aprovado quando obtém um valor igual ou superior ao estimado pela NBR 5413: salas de aula (300 lux); quadros negros (500 lux); salas de professores (300 lux). A uniformidade de iluminância (Un) é determinada através da relação entre a iluminância mínima (Emín) de uma superfície de trabalho e a média aritmética das iluminâncias $(\overline{\mathrm{E}})$ nesta superfície, considerou-se aprovado o ambiente que obteve um valor superior ou igual a 0,8$)$. 